\title{
Het waterbaljuwschap en een spectaculaire schipbreuk te Sluis in 1390 naar een ambtelijk verslag van dat jaar
}

\section{R. Degryse ${ }^{\circ}$}

Filips de Stoute, hertog van Bourgondië en graaf van Vlaanderen, was in januari 1390 in het bezit gekomen van een grote hulk, door hem genoemd "notre grand nef del Escluse". Hij had het vaartuig in Pruisen van de grootmeester van de Orde aldaar aangekocht en vervolgens naar Vlaanderen gestuurd, waar het te Sluis in de haven werd vastgemeerd. Midden januari kwam de hertog er persoonlijk zijn aanwinst bezichtigen ${ }^{1}$. Blijkbaar vertrouwde hij toen de zorg over het schip toe aan de toenmalige waterbaljuw van Sluis, Thomas van Sconeveld, die naderhand de supervisie over alles had.

De waterbaljuw had in de eerste plaats te zorgen voor de goede bewaking van het grote vaartuig en wel door de aanstelling van een bekwame stuurman en een tijdelijke bemanning van zowat twintig man, hun bezoldiging en bevoorrading, alsook de bestrijding van alle kosten en uitgaven die daarmee in verband stonden. Het ging dus om een voorlopige maatregel in afwachting dat het schip voor een of ander militair of commercieel doeleinde in dienst van de hertog kon worden ingezet.

Toen op 3 maart 's avonds en 's nachts een zware storm over de haven woedde, strandde de hulk met haar voorsteven op vaste grond nadat de meertouwen, waaraan zij met een viertal ankers vast lag, doorgebroken waren en ook een uitgeworpen vijfde anker het begeven had. Bij de pogingen om de stranding tegen te gaan verloor een lid van de bemanning het leven, doordat hij een slag kreeg van de "caeystoc", weggeslingerd door de orkaan.

Aanvankelijk was men van oordeel dat het schip op de strandingsplaats veilig lag, aangezien het niet beschadigd was en het met zijn achtersteven nog in het water bevond. Na een week stelde men ech-

- Hof ter Schriecklaan 33, 2600 Antwerpen-Berchem.

1 De grootmeester van de Duitse ridderorde in Pruisen in 1390 was Conrad Zöllner von Rothenstein. De eigenlijke naam van de hulk was "Marienborch". Het schip was door de hertog, na correspondentie daarover, aangekocht "aveuc tous ses apparans et les pourveances, armures, harnas et abillemens estans en ycelle". Als tegenprestatie voor de transactie zouden de hanzeaten uit Pruisen, tegen een toenmalige verbodsmaatregel van de hanze in, in Vlaanderen een partij lakens kopen. J. PAVIOT, La politique navale des ducs de Bourgogne 1384-1482, Rijsel, 1995, p. 50-51 en 89, noten 79-82 ; E. PETIT, Itinéraires de Philippe le Hardi et de Jean sans Peur, ducs de Bourgogne (1363-1419), Parijs, 1888, p. 216. 
ter ook vast dat het vaartuig op een van zijn zijden begon te kapsijzen en dat het zand, waarop de voorsteven rustte, geleidelijk wegspoelde. Er dook dus een reëel gevaar voor schipbreuk op, ook nadat de hellende scheepsboord door middel van manden gevuld met zand gestut was. De enige manier om het vaartuig ongedeerd uit zijn hachelijke toestand te redden, was het vlot te trekken, maar dan op het meest geschikte ogenblik. Als gevolg van dit manoeuvre, dat met behulp van twee schepen en twee schuiten ondernomen werd, ging de hulk evenwel reddeloos verloren. Deze schipbreuk gebeurde, naar berekend kan worden, op donderdag 10 maart. De twee stuurlui van het hertogelijk vaartuig, Jacob van Deventer en Pieter van Campen, die het noodlottig manoeuvre hadden laten uitvoeren, bleef niets anders over dan na de ramp onmiddellijk de wijk te nemen naar Vlissingen in Zeeland. Daar lieten zij de reddingsboot ("menre batel") van de hulk achter, en vluchtten verder.

Bij het vernemen van het nieuws over het verlies van zijn "grand nef" blijkt Filips de Stoute ten zeerste ontstemd te zijn geweest. Hij besloot dan ook een onderzoek te laten instellen naar de ware toedracht van het dubbele ongeval. In een hertogelijk schrijven van 28 maart, verzonden uit Dijon, stelde hij een drietal ambtenaren aan om de verantwoordelijkheid van de waterbaljuw van Sluis te onderzoeken. Het betrof meer bepaald de souverein-baljuw van Vlaanderen Jan de Visch (Jean li Pisson), heer van der Capelle (sire de la Chapelle), de controleur van de financiën Pieter Heyns en de schout van Brugge Sander Spierinc of twee onder hen om de enquête uit te voeren ${ }^{2}$. Het in het Frans gestelde verslag van de door deze commissie afgenomen getuigenissen, volgens het verhoor dat op 15 april te Sluis had plaats gegrepen, bleef in het departementaal archief te Rijsel bewaard ${ }^{3}$.

2 "Chers et bien amez. Nous avons sceu comment notre grand nef del Escluse a este pirie et froissiee dun bout a lautre, dont ik nous deplaist forment. Car nous tenons que ce vient par defaut du gouvernement de notre bailli del eaue et des autres qui avoient depar nous la garde dicelle. Et pour ce voulons savoir la verite du fait et par quel cas de force ou negligence il est avenu pour en avoir recours...". Hertogelijk schrijven van 28 maart 1390 gericht aan de drie leden van de door hem aangestelde commissie van onderzoek in genoemde zaak. Rijsel, Archives départementales du Nord, B1404/18315, verslag, waarin de tekst van de brief opgenomen is.

3 "Infourmacion secrete oye en la ville del Escluse le 15e jour davril lan mil CCC quatrevins et dix par le sire de la Chapelle, souverain bailli de Flandrez, Pierre Heyns, contrerolleur des comptes de notre tresredoubte signeur de Bourgoigne et de Flandres, et Sandre Spierinc, escoutete de Bruges. Au commandement de notre dit seigneur par ses lettres closes aux dessusdiz adrechans..." Ibidem, titel van het verslag opgesteld door de hertogelijke commissie na het verhoor van de getuigen en daarna ingediend. 
De onder eed afgelegde getuigenissen waren die van de volgende personen :

1. - Heer Simon van Brugdamme (messire Simon de Brugdam), kapitein van Sluis, en meester Gillis de Volder (mestre le Foulon), secretaris van de hertog (secretaire a notre dit seigneur). In hun uitvoerige uiteenzetting ging het eerst over de opdracht van de waterbaljuw inzake de zorg over de hulk, de aanstelling en bezoldiging van de tijdelijke bemanning en de geldmiddelen komende van het baljuwschap om alles te financieren. Vervolgens ging het over hetgeen beiden wisten over de stranding en de ondergang van het vaartuig en over de bijstand, die ze beiden aan de waterbaljuw door hun raadgevingen en begeleiding verleend hadden ${ }^{4}$.

2. - Thideman van Salich, geboren te Kampen, Nederduits zeeman (Thideman de Salich, alemant, nez de Campen, maronnier), oud 30 jaar. Hij behoorde tot de oorspronkelijke bemanning van het schip tijdens diens overtocht van Pruisen naar Sluis. Volgens hem viel er de waterbaljuw niets te verwijten ${ }^{5}$.

3. - Jehan de Brune (Jehan le Brune), scheepstimmerman (carpentier de nefs), oud 60 jaar. Hij was op 3 maart als lid van de bemanning gedurende de storm op het vaartuig. Hij ook verontschuldigde de waterbaljuw ${ }^{6}$.

4. - Liman meester Wolt (Liman mestre Wolt), geboren in Pruisen, zeeman, oud 42 jaar. Ook hij behoorde tot de oorspronkelijke bemanning van de hulk. Hij verontschuldigde de beide stuurlui, die om bestwil gehandeld hadden om het schip te redden. Tevens rechtvaardigde hij de waterbaljuw ${ }^{7}$.

5. - Willem fs. Jans (Guillaume filz Jans), sergeant van het water (sergent del eaue), oud 33 jaar. Hij bevond zich aan wal in gezelschap van de twee stuurlui van de hulk, toen 's avonds de orkaan losbarst-

4 " que par virtu dune commission patente de notre dit signeur adrechant au bailli de leaue et contenant que la dite nef il par le consel des deposans donroit a garde a un mestre maronnier..." Ibidem, getuigenis 1 .

5 "Et dist que selon son ensient un cescun fist le mieulx quil peut pour la nef avoir sauviee et que le bailli, la nef illec gisans, les vint visiter de jour en jour en priant de y mettre tout leur povoir et que plus est, requist au dit Jaque de prenre de gens assez et de non espargnier aucun coust, si que elle fust sauvee, quar il meismes ne si congnoissoit...". Ibidem, getuigenis 2.

6 "Et quant aux parlers du bailli a Jaque, bien croit que le bailli len parla pour le sauver, mais comment les parlers furent, il nest recors. Toutefuoiez daucune deffaulte que en peuist estre au bailli, il noit au dit Jaque faire aucune mencion...". De door getuige vermelde 3 maart 1390 viel op een donderdag, vermits de datum van paaszondag dat jaar 3 april was. Ibidem, getuigenis 3. Een week later, op donderdag 10 maart, was er de schipbreuk.

7 "quant est que le bailli le vint visiter et pour le faire sauver, dist comme dessus et nen sapperchut ne noy onques daucune deffaulte ou dit bailli...". Ibidem, getuigenis 4 . 
te. Hij wist ervan dat de waterbaljuw aan de eerste stuurman gevraagd had wanneer die dacht het gestrande schip vlot te laten trekken ${ }^{8}$.

6. - Aernout Bevelant (Ernoul Bevelant), sergeant van het water, 48 jaar oud. Hij sprak zich niet uit over zijn meester, de waterbaljuw.

7. - Jehan Slijp, baljuw van Sluis (bailli del Escluse), 42 jaar oud. Hij getuigde ten gunste van de waterbaljuw .

8. - Romboud de Voogd, klerk van de waterbaljuw (clerc dudit bailli), 50 jaar oud. Hij werd gepolst over het verbod door zijn meester aan de eerste stuurman van het schip opgelegd iets te ondernemen om het vaartuig vlot te trekken zonder dat beiden erbij aanwezig zouden zijn ${ }^{10}$.

9. - Alaerd van den Berghe (Alard de le Berghe), ontvanger van het grafelijk domein te Sluis (receveur de monseigneur a Lescluse). Hij verontschuldigde de waterbaljuw ${ }^{11}$.

10. - Jehan Bruneel, sergeant van het water (sergent de monseigneur au bailliage del eau). Hij verzekerde dat de waterbaljuw het vlot trekken van de hulk wou laten gebeuren in het bijzijn van hemzelf en van anderen, waaronder Simon van Brugdamme of Gillis de Volder en schipper Pieter Moerman ${ }^{12}$.

11. - Jehan de Coninck (Jehan le Roy), sergeant van het waterbaljuwschap. Hij wist dat de waterbaljuw, in verband met het voornemen de hulk vlot te trekken, raad had ingewonnen bij enkele stuurlui van "nefs", meer bepaald bij de reeds genoemde Pieter Moerman en drie andere schippers ${ }^{13}$.

8 "Dist oultre que au jeudi mesme jour que la nef fu muee, il oy que le bailli en parla au dit Jaque en demandant a savoir quant il entendoit de la dite nef faire mettre et tirer a leaue et que Jaque repondi neant devant demain. Ce dut avoir este au venredi...". Ibidem, getuigenis 5 .

9 "et noy onques complainte de Jaque de deffaulte de paiement ne daultre chose. Ains tient sur son serment selon quil en a puet avoir oy que le dit bailli sen est loyaulment a son milleur senz et pooir acquitez et par la plusque diligence quil povoit pour la dite nef avoir este sauvee...". Ibidem, getuigenis 7 .

10 "Dist par son serement que aultre chose nen scet, fors que le dit Jaque de Deventre avoit prins la nef en garde aux gens de monseigneur, pour combien il ne scet et quil oy dire au dit bailli, apres ce que la nef estoit pirije, quil avoit deffendu au dit Jaque que la dite nef il ne muast sans la presence de lui, le dit bailli...". Ibidem, getuigenis 8.

11 "Et quand est du dit bailli, selon son entencion, il en fist en toutes manieres toute sa diligence et tient que le dit Jaque nen pourra mettre aucune deffaulte ou coulpe sur le dit bailli...". Ibidem, getuigenis 9 .

12 "que selon son entendement le dit bailli sen acquita loiaulment par le milleur diligence quil povoit et que du commencement que la nef fu sur terre il ensemble messire Simon et maistre Gille le alla visiter et y eut des aultres maistres de nefs en prenant pour le sauvement dicelle tout le milleur consel quil pooit". Ibidem, getuigenis 10 .

13 "Et scet bien que le bailli y eut des autres maistres de nefs qui laviserent par noms Pierre Moerman, Piere de Cascopre, Guillaume filz Boudins, Michel 1 carpentier 
Deze getuigenissen waren omzeggens eensluidend. Hier en daar vulden ze elkaar inzake details wel aan. Als enige verantwoordelijken voor de mislukking van de redding van de hulk wezen ze de beide vertrokken stuurlui aan, in de eerste plaats Pieter van Campen, de tweede stuurman. Opvallend is verder dat geen enkele getuige de waterbaljuw in opspraak schijnt te hebben willen brengen. Deze laatste, Thomas van Sconeveld, wordt in het document zelfs niet bij naam genoemd. Deze discretie valt op, te meer daar vijf van zijn medewerkers door de hertogelijke commissarissen in verband met het optreden van hun overste aan de tand gevoeld werden. Allen waren het ermee eens dat de waterbaljuw zich niets te verwijten had en dat hij alleen maar gedaan had wat in dergelijk geval kon en moest gedaan worden. Het was niet hij, maar wel de tweede stuurman van het grote schip die eigengereid, de dag vóór de hoge vloed van 11 maart 1390, het initiatief zou hebben genomen de hulk vlot te trekken, dit tegen beter weten in ${ }^{14}$. Thomas van Sconeveld blijkt verder niet meer in verband met de ondergang van het schip door de hertog te zijn verontrust, vermits hij te Sluis als waterbaljuw tot 1396 in dienst bleef ${ }^{15}$.

Wat er ook van moge zijn, de tijdgenoten wisten heel goed dat een aan de grond gelopen vaartuig, althans een van middelmatige grootte, niet steeds reddeloos verloren was. Schepen van dat type werden overigens 's winters meestal tijdelijk in een zate of slijkerige kuil aangemeerd, in afwachting met de lente opnieuw voor de scheepvaart of

de nefs et aultres, et en fist toute la plus grant diligence et le mieux quil povoit pour le avoir sauvee". Ibidem, getuigenis 11.

14 "sur la rue ou il oy que le dit bailli dist au dit Jaque de Deventre que nullement ycellui Jaque ne mouvast la dite nef, il le dit bailli ne fust dellez, quar il avoit entencion de y admener le dit messire Simon de Brugdam, le dit mestre Gille le Foulon ou lun des deux et aultres maistres de nefs, especialment Pierre Moerman, quil lui oy nommer et fu lors advise selon son souvenance, quon nen feroit aucune chose devant le venredy lors prochain venant, pour ce que a dont a leur adviz devoit estre le plus haulte eaue et furent 2 grosses nefs et 2 appelez schutes envoiees au lieu pour aidier au fait. Ce non obstant, si quon dist communaulment, le dit Pierre en labsence de Jaque travilla la nef avant le dit venredy, ne scet pas le jour, et ainsi brisa". Ibidem, getuigenis 10 .

$15 \mathrm{Hij}$ was waterbaljuw van 2 november 1387 tot 19 april 1395. J. VAN ROMPAEY, Het grafelijk baljuwsambt in Vlaanderen tijdens de Bourgondische periode, Brussel, 1968 (Verhandelingen Koninklijke Vlaamse Academie voor Letteren, Wetenschappen en Schone Kunsten, Klasse der Letteren, nr. 62, p. 645, met verwijzing naar Rijsel, Archives départementales du Nord, nrs. B625 en 23298. Naderhand van 1399 tot 1404, zien we "Thomas Scoenvelt" nog de functie bekleden van baljuw van Brugge en het Brugse Vrije. L.P. GACHARD, A. PINCHART en H. NELIS, Inventaire des Archives des Chambres des Comptes, Brussel, 1837-1931, dl. II, p. 358. 
zeevisserij te worden ingezet ${ }^{16}$. Zo iets gold blijkbaar niet voor een "grand nef", want die ging op de rede of in de haven voor anker.

Met de term hulk werd in de late middeleeuwen over het algemeen een groot vrachtschip met een mast, een razeil en een ingebouwd voor- en achterkasteel bedoeld. Het was een kielschip met vooraan en achteraan afgeronde stevens. Na 1400 kon een grote eenheid van dat type een draagvermogen van 200 last en een lengte van zowat 100 voet bereiken, maar dat bleef toch uitzonderlijk ${ }^{17}$. Feitelijk betekende de grote hulk als scheepstype het eindresultaat van het bouwen van steeds grotere vaartuigen, met al de nadelige gevolgen van dien, waaronder vooral de verminderde stevigheid van de verbanden. Het was inderdaad een schip met boorden in overnaadse klinkbouw en op spanten en soms doorbalkt, steunend op langscheepse verbanden. Vergeten we daarbij niet dat de middeleeuwse vaartuigen houten constructies waren en dus in bepaalde situaties zeker fragiel. Sommige schippers zagen zich dan ook vroeg of laat met schipbreuk geconfronteerd ${ }^{18}$.

Hoe de grote hulk van Filips de Stoute er kan hebben uitgezien kunnen we grosso modo nagaan op de afbeelding van dergelijk vaartuig op het zegel van de hanzestad Danzig (Gdansk) van 1400. Het toont ons een schip met boorden in klinkbouw, een ingebouwd voor- en een achterkasteel, een boegspriet en een midscheepse mast voorzien van een stag, een mastkorf en het touwwerk van de want, maar zonder ra noch razeil ${ }^{19}$.

In het verslag over de ramp met de hertogelijke hulk vinden we ook enkele nautische termen als "menre batel" (bootje, reddingsboot), "schute" (schuit), "nef" (schip), "ancre" (anker), "cable" (kabel), "caeystoc" (kaaistok), "carpentier de nefs" (scheepstimmerman), "maistre de nef" (stuurman, schipper) en ook het woord "chep" voor schip $^{20}$.

16 "Item, gisent sur la waze oudit port 12 vasseaulx de Amburg en Alemagne vagues, sans maistres et sans maronniers, comme coghes, boeyers, craeyes et eevers, qui sont pesans vasseaulx et mais a la voile. Item gisent illecq sur la wase environ 36 ou 40 buusses, qui sont vasseaulx pour peschier harrens et poissons et ne servent a aultre chose". R. DEGRYSE, De schepen in de haven van Sluis in het voorjaar 1464, in : Mededelingen van de Marine Academie. Boek XX, 1968, p. 95-106, bijlage 1, p. 102, stuk van omstreeks 1 januari 1464.

17 G. ASAERT, Westeuropese scheepvaart in de Middeleeuwen, Bussum, 1974, p. 105 ; J. VAN BEYLEN, Scheepstypen, in : Maritieme Geschiedenis der Nederlanden, dl. I, Bussum, 1976, p. 121-124 ; J. PAVIOT, o.c., p. 295.

18 C.M. PLEYTE, Van hulken en karvelen. Scheepsbouw in de XVe eeuw, in : Biekorf, 45 (1939), p. 18-22.

19 H. EWE, Schiffe auf Siegeln, Bielefeld-Berlijn, 1972. Einführung p. 14 en SiegelKataloog, p. 128, nr. 53, tekening naar de kleurenfoto op p. 36.

20 Verslag van de getuigenissen, passim. 
$\mathrm{Na}$ het verlies van de grote hulk bleef Filips de Stoute nog in het bezit van een andere "grande neif", de Sint-Christoffel, eveneens in Pruisen gekocht en sinds 1390 verhuurd. Dit schip werd in 1395 door zeelui van de koningin van Napels gekaapt. Daarna zien we voor lange tijd de hertogen van Bourgondië afzien van het bezit van een of ander schip ${ }^{21}$.

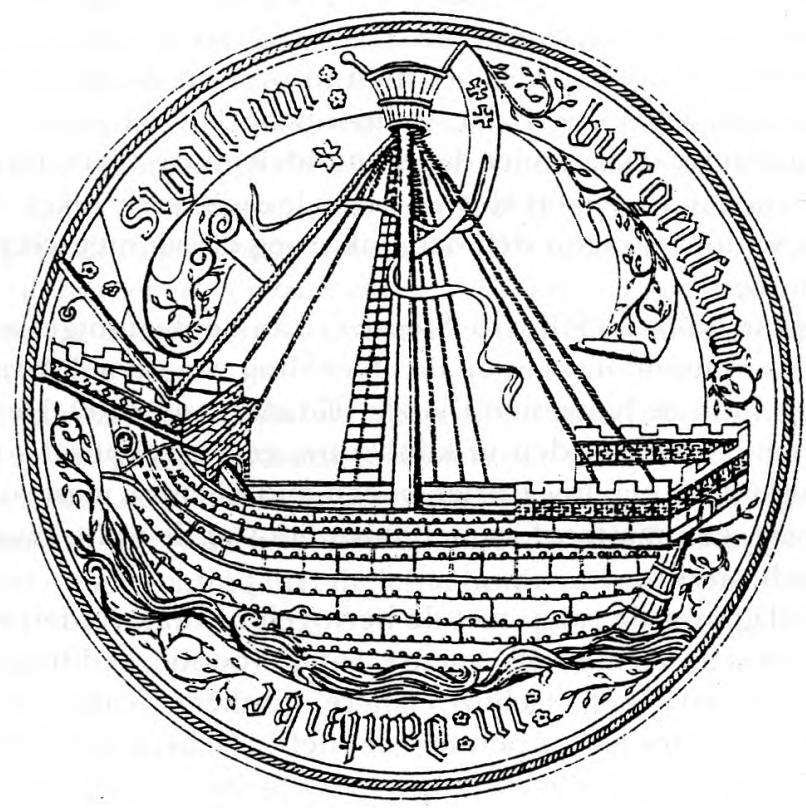

Grootzegel van de hanzestad Danzig (heden Gdansk) in Polen, in het voormalige Pruisen van de Duitse ridderorde, met de afbeelding van een hulk en met het randschrift "Sigillum burgensium in Dantzike" gehecht in rood was aan een oorkonde van 9 juli 1462. Lübeck, stadsarchief. De afbeelding op de stempel klom op tot 1400. (Uit : Herbert Ewe, Schiffe auf Siegeln. BielefeldBerlin, 1972, p. 36 : foto en p. 128 , nr. 53 : tekening.

21 J. PAVIOT, o.c., p. 50 en 89, noten 73-77 ; R. DEGRYSE, De admiraals en de eigen marine van de Bourgondische hertogen, in : Mededelingen van de Marine Academie, boek XVII, 1965, p. 139-225. Zie p. 146, noot 25. 


\section{Bijlage}

Verklaring onder eed afgelegd door Thideman de Salich uit Kampen, lid van de bemanning nopens zijn belevenis met de hulk van de hertog, 15 april 1390

Uittreksel uit het rapport opgesteld door de commissie van onderzoek naar de verantwoordelijkheid voor de ramp met het hertogelijk vaartuig.

Rijsel, Archives départementales du Nord, B1404/18315.

Thideman de Salich, alemant nez de Campen, maronnier del eage de XXX ans. Jurez et requis sur tous les poins et circonstances du dit fait.

Dist que lui XXe de companions maronniers il fut dedens la dite nef ou temps de toute la tempeste et furent tous leuwez pour la garde dicelle par le dit Jaque leur mestre a 1 franc cescun par mois et leurs fraiz et des quelz lun fu tuez ou mesme temps par un cop dont cellui fu atteint dun engien quil ont en la nef appelle caeystoc, qui leur de force par le tresgrant tempeste eschapa.

Requiz se Jaque et Pierre y fyrent dedens. Dist que Pierre ny fu pas, mais Jaque y fu a commencement, quant on sapperchut quil feroit si grans vent. Et pour ce quil le veoit si doubiteux, se mist a terre en la ville del Escluse pour avoir admene en la dite nef plus de gens. Et dedens ce quil fu pour ce envois, le vent sefforca de tel maniere quil ne peut revenir, quar le temps fu tel que nul homme par bateaux ne aultres vaissaux ne euissent peu venir et quar onques si grant ne si dur tempeste sur mer ne veu comme en ce temps estoit. Et ainsi demora Jauqe aussi dehors. Et exepte cette nuyt, pas ne sceut que le dit Piere fust hors. Dist oultre que en la nuite les IIII ancres quil avoient hors rompirent et aussi le Ve quil jeterent, la nef lancha a terre, parce que la nef fu trop prez de la terre avant que celle ancre peust attacher. Et dist que dedans sa vie. Onques si perilleux temps ne vy sur mer, quar a tres grans paine se pouoient il tenir dedens la nef.

Requis le nef ainsi estant a terre, ou elle avoit este environ VII ou VIII jours, par qui, par quel consel et commandement de qui elle fu muee et tiree pour avoir a leaue. Dist que le dit Piere, voyans se quil lui sembla que la nef commenchoit a incliner a lun leis par leaue qui croissoit et qui emportoit le sauvelon et aians parce doubte que elle peuist avoir brisie. Commencha en labsence de Jaque a faire tirer ala dite nef, lequel Jaque lors estoit en la ville pour y avoir admene plus grand aide et manda que a la dite nef pas il ne fesist tirer, se elle ne flotast, neant mains le dit Piere lavoit encommenchie a tirer vers leaue et le dit Jaque venant illec, le trouva tirant et y aida aussi, dis- 
ans a Pierre : je doubte que trop tempre vous avez commenchie. Piere dist: Jaque, la nef commencha a incliner sur lun des leis, parce que le sauvelon lui eschapa. Et par ainsi tirerent le nef bien II toises loings hors de son lieu vers leaue et dedens ce leaue abaissa et la nef se inclina vers lun leis, tant que elle rompi, pour la quelle chose les dit Jaque et Pierre menerent tres grans duel, disans : Elas, que ferons nous et au derrain dist le dit Jaque : Il faut milleur tractier estans es bois que seans ou chep, et prinrent incontinent le menre batel de la dite nef et par ycelle se absenterent vers Zeellande, si quon dist. Et dist que selon sen ensient un cescun fist le mieulx quil peut pour la nef avoir sauvee et que le bailli, la nef illec gisans, les vint visiter de jour en jour en priant de y mettre tout leur povoir et que plus est, requist au dit Jaque de prenre de gens assez et de non epargnier aucun coust, si que elle fust sauvee, quar il meismes ne si congnoissoit. Dist oultre que il qui depose et les aultres compaignons porterent journelement a le hote le sauvelon arriere aux costez de la nef, au fait que par leaue il estoit entors et amenry [a].

Requis du peaement [b] et se le dit Jaque eust du dit bailli aucune deffaulte de chose qui lui peust estre necessaire pour le sauvement de la nef. Dist par son serment que onques au dit Jaque nen oy faire complainte et mesmez ne sen appercut onquez, mais tient que aucune deffaulte le dit Jaque nen avoit.

[a] Entors : ontwrichting. Amenry : verminderd.

[b] sic : paiement. 